\title{
Aplicação da manufatura enxuta em uma indústria de equipamentos agrícolas
}

\author{
Application of lean manufacturing in an industry of agricultural equipments \\ Ana Paula Barth Bartz ${ }^{1} \quad$ Andreas Dittmar Weise $^{1} \quad$ Janis Elisa Ruppenthal $^{1}$ \\ Recibido 28 de noviembre de 2011, aceptado 9 de noviembre de 2012 \\ Received: November 28, $2011 \quad$ Accepted: November 9, 2012
}

\begin{abstract}
RESUMO
Com a crescente concorrência e a necessidade de maior competitividade, as empresas que adotam o sistema de produção enxuta levam vantagem sobre as demais, pois tratam melhor as informações aumentando a sua eficiência. O objetivo desta pesquisa foi diminuir o lead-time da organização estudada, através da aplicação prática do Just-in-time em busca de uma produção enxuta em uma empresa metal-mecânica, fabricante de implementos agrícolas. Para atender a este objetivo realizou-se um estudo de caso de natureza qualitativa e de ordem descritiva. Para a coleta de dados utilizou-se inicialmente a observação e a análise documental para entender o processo produtivo. Após trabalhou-se com levantamentos de dados através de entrevistas estruturadas para identificar as dificuldades enfrentadas pelos fornecedores na entrega dos insumos dentro das especificações acordadas. A empresa estudada apresentava alto índice de atraso na entrega de seus produtos, devido ao elevado lead-time. Através da elaboração do mapeamento de fluxo atual, identificou-se que a organização trabalhava com uma produção empurrada e que muito dos atrasos ocorriam por problemas no fornecimento de insumos. Buscou-se a eliminação de tarefas que não agregavam valor ao produto final, elaborou-se um fluxo de valor enxuto para o processo, identificaram-se os principais problemas que levavam os fornecedores a entregarem os insumos fora das especificações ou dos prazos e sugeriram-se ações que poderiam ser aplicadas para eliminação destes atrasos. Através destas ações observou-se a redução no lead-time, auxiliando no melhor atendimento dos prazos de entrega, no aumento da competitividade, fato relevante para manter-se no mercado atual de equipamentos agrícolas.
\end{abstract}

Palavras-chave: Produção enxuta, lead-time, equipamentos agrícolas, melhoria de processos, competitividade.

\section{ABSTRACT}

With increasing competition and the need for improved competitiveness, companies who adopt the lean production system have some advantages, because they deal better with the information, increasing their efficiency. The objective of this study was to decrease the lead-time required by the studied company, by practical application of just-in-time searching for lean production in a metalworking company, manufacturer of agricultural implements. To meet this purpose, a case study of qualitative and descriptive order was carried out. To collect data, observation and documental analysis were performed, in order to understand the production processes, then working with the collection of data, through structured interviews in order to identify the difficulties encountered by suppliers in providing the supplies within the agreed specifications. The company had high indexes of late delivery of their products because of the high lead-time. Through the development of the mapping of actual flow, it was found that the organization was working with a production pushed and much of the late occurred because of problems in the supply of inputs. By eliminating tasks that did not add value to the final product, a lean value flow was produced for the process, identifying the major problems which caused the suppliers to provide the supplies out of specification or out of date and suggested actions that could be implemented for the elimination of these

\footnotetext{
1 Universidade Federal de Santa Maria. Avenida Roraima, 1000. Centro de Tecnologia, Sala 305, Cidade Universitária, 97.105900, Santa Maria - RS - Brasil. E-mail: anabartz@gmail.com; andreas.weise@ufsm.br; profjanis@gmail.com
} 
delays. Through these actions, the reduction in lead time was observed, helping to better meet delivery deadlines, increased competitiveness, a relevant fact to keep in today's market of agricultural equipment.

Keywords: Lean manufacturing, lead-time, agricultural equipment, process improvement, competitiveness.

\section{INTRODUÇÃO}

O termo Lean Manufacturing, ou produção enxuta, tornou-se conhecido após a publicação do livro "A máquina que mudou o mundo" de Womack, Jones e Roos em 1990. O livro apresenta um estudo sobre a indústria automobilística mundial e evidencia enormes diferenças na qualidade, produtividade e demais benefícios trazidos pelo Sistema Toyota de Produção.

Taj [24] afirma que a produção enxuta nasceu na Toyota com o nome de Just-in-time - JIT ou Sistema Toyota de Produção - STP. Para Hallgren e Olhager [9], os conceitos de produção enxuta são sinônimos de práticas desenvolvidas pelo STP, sendo que as técnicas de produção enxuta são semelhantes às usadas pelas empresas que operavam até então com o sistema JIT. Já Marksberry, Badurdeen, Gregory e Kreafle [13] afirmam que STP e produção enxuta são a mesma filosofia de trabalho, sendo o segundo termo mais comumente utilizado no ocidente para referir-se ao modelo de produção proposto pela Toyota, na década de 1970.

Independente da denominação utilizada, este sistema tem como objetivo minimizar os desperdícios existentes na organização. Isso leva a um fluxo contínuo, minimizando o lead-time do processo e elevando o nível de qualidade através da melhoria contínua tanto dos processos como dos seus produtos. Baudin [4] salienta que as organizações não alcançam a competitividade unicamente através da redução dos seus custos, mas da resposta às variações da demanda. Neste sentido pode-se considerar o JIT como uma ferramenta que pode auxiliar fortemente também na busca por competitividade no âmbito organizacional.

Este artigo propõe a aplicação prática da produção enxuta em uma empresa fabricante de equipamentos agrícolas. O principal problema encontrado na empresa foi o alto lead-time, tempo desde a entrada do pedido até a entrega do produto ao cliente. Nesse caso, os clientes são as revendas autorizadas que atendem aos produtores rurais. Esse lead-time alto provocou diversos atrasos na entrega de produtos, o que cria uma cultura negativa entre os departamentos de vendas e produção: "não se vende porque não possui capacidade de produzir" ou "não se produz mais porque não se vende".

Para resolver esse problema foi realizado um estudo de caso, de natureza qualitativa e de ordem descritiva, desenvolvido através das seguintes etapas: mapeamento do processo desde os fornecedores até a revenda; análise das atividades e tarefas identificando as que não agregavam valor ao produto; proposta de novos métodos de pré-montagem; proposta de novos métodos para a montagem final e proposta de novo modelo de logística entre a empresa estudada e os fornecedores analisados.

A coleta de dados para a realização deste estudo desenvolveu-se em dois momentos. Inicialmente utilizou-se a observação e análise documental para que os pesquisadores conhecessem o processo produtivo. Num segundo momento trabalhou-se com levantamento de dados que se realizou no período de 24 de agosto até 15 de setembro de 2011 através de entrevistas estruturadas com os fornecedores analisados. Estas entrevistas foram realizadas com o gerente industrial dos fornecedores com o maior índice de atraso/entrega de produtos fora das especificações, buscando-se identificar as causas de tais problemas. Com base nestes dados propuseram-se ações de melhoria em ambas as partes como forma de introduzir uma parceria entre a empresa estudada e os fornecedores analisados.

\section{O JUST-IN-TIME E A CADEIA DE PRODUÇÃO}

O enfoque de cadeia produtiva é útil para auxiliar na organização e controle do macro processo produtivo de uma organização. Isso auxilia na identificação e eliminação dos gargalos produtivos e na implantação de melhoria contínua e de novas técnicas de gestão. Com a utilização desse modelo de mapeamento, pode-se aplicar a metodologia da 
cadeia de produção para todos os setores de negócio, sejam esses indústria ou serviços [6].

Pires e Neto [18] caracterizam uma cadeia de suprimentos como o envolvimento de processos de clientes e fornecedores, desde que haja uma ligação da matéria-prima ao produto final. Consideram, ainda, que o principal objetivo das cadeias de suprimentos é atender o consumidor final com maior eficácia, entregando o produto ou serviço com maior valor agregado e menor custo.

Com a introdução de técnicas de produção enxuta como o JIT, cada vez mais se torna indispensável a relação estreita de parceria entre os participantes da cadeia produtiva [2]. Isso faz com que os requisitos da filosofia JIT como entrega no prazo, qualidade e quantidades corretas sejam cumpridos. Para tanto, salientam que a gestão da cadeia de suprimentos, ou de produção, reduza o número de fornecedores de cada parte do produto, permitindo um maior envolvimento e cooperação dos fornecedores no desenvolvimento do produto. A Figura 1 mostra esses pressupostos.

Com a utilização do modelo apresentado na Figura 1, os participantes de uma cadeia de produção avaliam e adéquam sua estrutura; reduzindo o número de fornecedores, melhorando as atividades e processos, criando um fluxo integrado de materiais e informações, o que melhora a eficiência da cadeia. Além disso, deve haver um alinhamento entre as

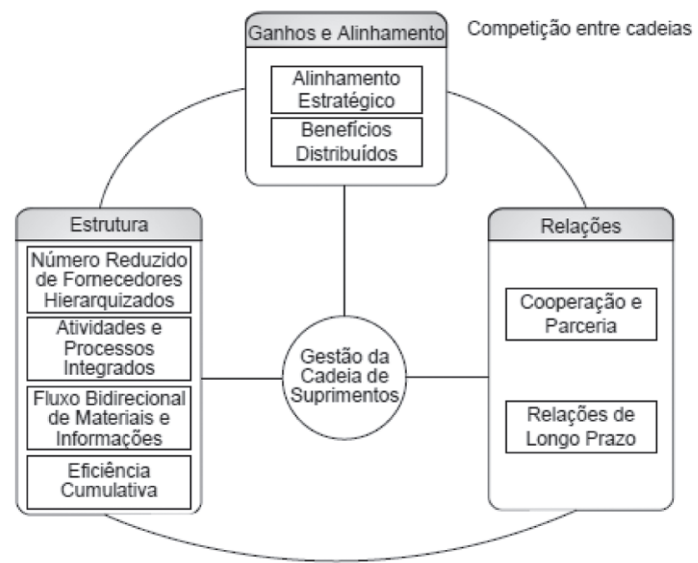

Figura 1. Pressupostos da gestão da cadeia de suprimentos.

Fonte: Alves F., Cerra, Maia, Neto e Bonadio [2] estratégias dos participantes para que haja resultado positivo mútuo.

Isso se consegue com a formação de parcerias e relacionamento de longo prazo entre os participantes da cadeia.

\section{SISTEMA TOYOTA DE PRODUÇÃO - LEAN MANUFACTURING}

O modelo de produção enxuta começou a ser planejado após o final da segunda guerra mundial, no Japão, quando executivos da Toyota, liderados por Taiichi Ohno, perceberam a grande diferença de produtividade existente entre a indústria automobilística japonesa em comparação com a americana [10]. A partir desta observação, iniciaram-se muitos estudos e pesquisa sobre qual o fator desta diferença. $\mathrm{O}$ resultado mais relevante apontado pelas observações foi de que a mão-deobra japonesa era mal utilizada. Eram necessários, em média, nove japoneses para realizar o trabalho feito por um americano.

A partir desta descoberta iniciou-se um incessante trabalho para a redução dos desperdícios. Para que fossem alcançados os objetivos, criaram-se meios de estabelecer fluxos contínuos e sincronismo durante a produção. Foram adotadas ferramentas como a autonomação (que auxiliou na resolução da causa raiz dos problemas e no desenvolvimento de toda a filosofia Lean) e o JIT (técnica usada para controle visual da produção e entrega de materiais, evitando paradas da força de trabalho, falta de material e outros).

O STP nasceu da necessidade da indústria japonesa em alcançar os índices de produtividade americanos. A partir desta necessidade, desenvolveu-se uma nova filosofia para gerenciar as organizações. Shingo [23] afirma que as principais características do sistema Toyota são de que o sistema prima pela produção de pequenos lotes e grandes variedades a custos baixos e a interligação de processos com a montagem final, gerando ciclos curtos, inventários reduzidos e equilíbrio na carga de trabalho. Os principais princípios para a sustentação do sistema são o JIT e a autonomação.

O JIT é uma estratégia de produção com o objetivo de eliminar estoques. Implantar esta ferramenta significa 
ter as peças certas, no local certo, na quantidade certa e com a qualidade combinada. O desenvolvimento do sistema kanban foi o meio encontrado para o controle visual das informações de que peças os processos iniciais devem produzir para atender as necessidades dos processos seguintes. "Just-in-time é muito mais do que um programa de redução de estoques. Just-in-time é uma ampla estratégia de produção com o objetivo de reduzir os custos totais e melhorar a qualidade do produto em operações de fabricação" [16]. A autonomação é uma evolução da automação pura. Com seu desenvolvimento podese fazer com que um mesmo operador cuidasse de várias máquinas, pois estas eram preparadas para parar quando completavam uma operação ou sempre que apresentavam condições anormais de trabalho. O uso da autonomação faz com que a atenção fique voltada para a resolução dos problemas.

Baseado nos princípios da redução dos desperdícios e evoluindo o modelo, Liker [10] define Lean como sendo o modelo que visa reduzir o tempo entre o pedido do cliente e a entrega do produto, pela eliminação dos desperdícios e melhoria contínua.

\section{JUST-IN-TIME - JIT}

O JIT é uma filosofia de gestão que tem por objetivo principal a produção e entrega de seus produtos na quantidade certa, no local certo, com a qualidade desejada e no tempo correto [11]. Cabe salientar que para o melhor entendimento da filosofia, melhor seria o termo "Just-on-time", visto que um dos fatores de insucesso é a intenção das empresas em anteciparem a produção para atender ao tempo de entrega. Isso provoca superprodução, ocupação dos espaços e gera inventários, que são consideradas perdas clássicas nos processos de produção. Assim, para que se alcance o JIT, outras ferramentas de auxílio à produção devem ser implantadas, como o kanban, e sincronização da produção.

Muitas empresas tentam implantar o JIT, porém não obtém sucesso em suas aplicações pelo fato desta ferramenta ter sido desenvolvida baseada na cultura oriental, a qual é muito diferente da nossa cultura ocidental [10]. A cultura pode ser definida como uma programação mental de um grupo ou uma sociedade formando uma identidade coletiva que influencia na interpretação da realidade [12]. Neste sentido entende-se porque Liker [10], Rodrigues e Hatakeyama [20], Arca e Prado [3] e Ahuja e Khamba [1] afirmam que somente alcança-se sucesso na implantação da produção enxuta quando a organização adapta estas ferramentas a sua cultura organizacional.

Cudney e Elrod [7] salientam que a manufatura seguindo um modelo enxuto pode ser aplicada em todo o processo, bem como em um produto específico. Isso varia de acordo com as necessidades e possibilidades de cada organização. Assim, consideram que as empresas consideradas mais ágeis possuem foco nos clientes e não em seus processos internos.

Boyle e Scherrer-Rathje [5] apresentam que muitas pesquisas foram realizadas, mas poucas apresentam a relação entre a produção enxuta e a flexibilidade do processo produtivo. Isso, muitas vezes ocorre porque as organizações implementam parte das ferramentas para se alcançar a manufatura enxuta por obrigação de clientes ou acreditam que as ferramentas são de aplicação simples. O fato é que para que o sistema opere com flexibilidade e de forma enxuta, todos os processos envolvidos devem ser aprimorados para tal.

O conceito de operação segundo o JIT apresenta sete princípios fundamentais: eliminação de desperdícios, sistema puxado - kanban, fluxo contínuo de trabalho, controle total da qualidade, compromisso da alta administração e dos empregados, relação de longo prazo com fornecedores e melhoria contínua dos processos - kaizen [17]. Ainda, consideram que esses princípios devem ser redefinidos para cada tipo de aplicação, seja de manufatura ou serviços, pela necessidade de construção de um modelo de implantação de acordo com os objetivos do negócio da organização.

A falta de uma estratégia consistente de gestão afeta a competitividade das organizações no longo prazo [15]. Por isso, salienta que as empresas JIT, ou seja, empresas que aplicam eficazmente as técnicas de manufatura enxuta são mais bem-sucedidas que outras que não aplicam. Ainda acrescenta outro princípio, além dos sete apresentados anteriormente, $\mathrm{o}$ respeito às pessoas.

Para que se alcance o sucesso e obtenha-se um processo JIT, algumas ferramentas são comuns a 
todos os tipos de empresa, como o programa $5 \mathrm{~S}$; a melhoria contínua na busca da simplificação das atividades e tarefas componentes de um processo; o balanceamento da produção para que se alcance o fluxo contínuo de materiais; mudanças de leiaute para que se consiga reduzir o número de pessoas e a movimentação destas; criação de "supermercados" de material em processo em diferentes locais, visando à redução de inventários e buscar a flexibilização da produção para diminuir os lotes e ter uma produção mista [10].

O JIT tem sido um elemento fundamental para alcançar a produção enxuta nas organizações. Ainda, consideram que o termo JIT originou-se a partir do conceito de redução de estoques e salientam, também, que as peças devem ser entregues aos clientes a tempo de serem utilizadas e nunca antes desse tempo [19].

Para Germain, Dröge e Daugherty (1994) citados por Green Jr., Inman e Birou [8], a filosofia JIT pode ser aplicada nas funções internas de manufatura, compras e outros setores da organização. Após a aplicação interna pode-se desenvolvê-lo para aplicar externamente à organização, como meio de vantagem competitiva de diferenciação dos processos de entrega de produto, em que a relação comprador-vendedor é fundamental para o sucesso do JIT.

Segundo Matson e Matson [14], de acordo com sua pesquisa de campo, os maiores problemas encontrados na aplicação do JIT durante a cadeia produtiva são:

a) Fornecedores: tempo de entrega, tempo de reação à alteração de demanda, qualidade das peças fornecidas, lead-time, falta de comunicação e problemas relacionados a produtos em atraso;

b) Centro da cadeia de produção: qualidade do produto, manuseio de material, treinamento, nível de habilidade empregado, trabalho em processo de inventário, disponibilidade de trabalho, capacidade de produção limitada e inventário de peças acabadas;

c) Clientes: mudanças nos horários de necessidade de recebimento, previsões falhas, transportadores e falta de comunicação.
Taj e Morosan [25] apontam seis práticas JIT: redução do tempo de setup; flexibilidade de programação; manutenção; leiaute de equipamentos; Kanban e relações JIT com fornecedores. Ainda, apresentam outras práticas, chamadas de práticas de infraestrutura, que são gestão da qualidade, gestão da força de trabalho, estratégia de produção, características organizacionais e design de produto.

Para a medição do desempenho da produção sugerem análise do giro de estoque; do índice de entregas no prazo; o lead time e o tempo de ciclo.

\section{O FLUXO DE VALOR}

Analisar o fluxo de valor significa identificar todas as tarefas necessárias para que um produto fique pronto, independente de agregar ou não agregar valor a este. Para cada produto têm-se, basicamente, dois fluxos essenciais: o fluxo de produção, desde a matéria-prima até a entrega; e o fluxo de projeto de produto, desde a concepção até o lançamento. Considerar a perspectiva do fluxo de valor significa levar em conta o quadro mais amplo, não só os processos individuais; melhorar o todo, não só otimizar as partes. Se for observado o todo e percorrido o caminho necessário para a fabricação do produto, desde a extração da matéria-prima até o consumidor, o fluxo de valor de um produto passará por várias empresas e até outras unidades produtivas [22]

O mapeamento do fluxo de valor é considerado uma das atividades mais importante do processo de implantação de um sistema de manufatura enxuta, pois identifica os trabalhos com valores agregados ou não [10]. O mapeamento do fluxo de valor é conhecido na Toyota por mapeamento do fluxo de informações e material, e aborda três fluxos da manufatura: materiais, informações e pessoas/processos. O mapeamento do fluxo de valor tem por objetivo mapear o fluxo atual (materiais e informações) e o fluxo ideal, o fluxo melhorado (mais "limpo") para executar o caminho realizado pelo produto.

Quando se pensa em fluxo de valor no chão-defábrica, o que se imagina primeiramente é o fluxo de material. Mas tão ou mais importante é o fluxo das informações, pois o diferencial entre empresas 
pode ser este fluxo, isto é, como lançar a informação certa, ao setor certo somente quando necessário. A Toyota pensou nisto, com processos sincronizados e implantando a produção puxada. Com este sistema de produção a informação é lançada para apenas um setor e este "puxa" o material necessário de seus fornecedores, para produzir o solicitado. A Figura 2, mostra o funcionamento do sistema puxado de produção.

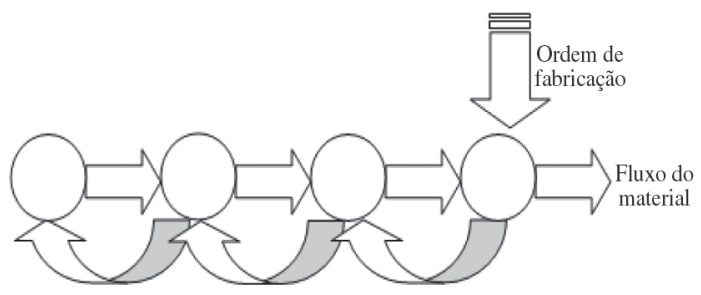

Figura 2. Sistema puxado de produção.

Fonte: Moura [16].

O uso do mapeamento do fluxo de valor torna-se então, ferramenta indispensável na identificação de desperdícios e ainda contribui para adequar os processos da empresa aos princípios lean, contribuindo para a melhoria do desempenho dos processos, dos fluxos e proporcionando maior integração entre todas as etapas deste.

\section{FLUXO DE VALOR ENXUTO}

Um fluxo com esta característica apresenta um processo que produz somente o necessário para o processo seguinte. Isso conseguido auxiliará na redução de muitos desperdícios relacionados à superprodução, como produtos defeituosos, espera e movimentação. Além disso, identificará as causas destes desperdícios, o que se torna ainda mais importante para as empresas.

O que se busca com a produção enxuta é obter um processo que produza somente o que o próximo processo necessita e quando necessita. Assim, tenta-se interligar todos os processos - desde o consumidor final até a matéria-prima - em um fluxo regular sem retornos que gere o menor lead-time, e a mais alta qualidade e o custo mais baixo [22].

Segundo estes mesmos autores, para se conseguir um fluxo de valor enxuto podem-se seguir os seguintes passos: produzir de acordo com o takt-time (que sincroniza o ritmo de trabalho da produção para acompanhar o ritmo de vendas); desenvolver fluxos contínuos onde for possível; usar o kanban, onde o fluxo contínuo não for possível; tentar enviar a programação do cliente para somente um processo de produção; nivelar o mix de produtos (distribuir a produção de diferentes produtos uniformemente no decorrer do tempo no processo puxado); nivelar o volume de produção; e, desenvolver a habilidade de produzir as mesmas peças todos os dias nos processos anteriores ao processo puxado.

\section{ESTUDO DE CASO}

A empresa estudada é uma instituição de pequeno porte. Rodríguez-Ponce, Pedraja-Rejas, Delgado e Rodríguez-Ponce [21] define as organizações de pequeno e médio porte como aquelas que possuem de 10 a 50 trabalhadores e os proprietários tendem a centralizar as informações. Esta organização está localizada na região centro-oriental do Estado do Rio Grande do Sul, possui área construída de 1.000 $\mathrm{m}^{2}$ e produz equipamentos agrícolas. Possui duas linhas de produtos, sendo que para este trabalho foram analisados os dados de uma dessas. Fazem parte desta linha, sete produtos com dezessete configurações diferentes, possibilitadas através da instalação de acessórios de controle para agricultura de precisão.

Para a fabricação dos produtos estudados são utilizados materiais importados comprados de revendedores nacionais, peças adquiridas de fornecedores desenvolvidos para essa finalidade e peças fabricadas internamente na empresa. Para fabricar essas peças e montar o produto com qualidade e agilidade, o setor produtivo está dividido em três partes: fabricação de peças e componentes, pintura e montagem. O setor de pintura é responsável pela aplicação dos revestimentos contra corrosão, como wash-primer, primer e tintas. Já o setor de montagem realiza a montagem das peças recebidas dos fornecedores, internos e externos, e realiza os testes finais de funcionamento de cada equipamento.

Para a fabricação do modelo básico são utilizados quatro componentes importados adquiridos no mercado nacional e oitenta e nove itens nacionais. Para o modelo intermediário são utilizados cinco componentes importados, visto que o sistema eletrônico de controle é de fabricação alemã, sendo o mesmo número de componentes nacionais. $\mathrm{O}$ 
modelo completo, com dispositivos para agricultura de precisão, é fabricado com quatro componentes importados e noventa e dois nacionais. Todos os componentes importados são adquiridos de um único fornecedor no Brasil, enquanto que os componentes nacionais são comprados de quatorze diferentes fornecedores.

Considerando o problema enfrentado pela organização, alto lead-time, juntamente com informações obtidas através de indicadores de vendas que demonstram uma demanda maior pelo modelo básico, optou-se por iniciar as atividades de implantação de manufatura enxuta nesta linha de produção.

Para a fabricação do produto, alguns itens necessários são projetados e desenvolvidos pelos fornecedores exclusivamente para a empresa estudada. Isso é realizado para caracterizar o produto com a identidade proposta pela empresa, de fortalecer o design de sua marca. O problema encontrado pela empresa, de alto lead-time, iniciou por esta diferenciação no produto, o que obrigou alguns fornecedores a realizarem mudanças em seus processos para fabricar o componente de acordo com o projeto e especificações solicitadas.

Os componentes especiais envolviam cinco fornecedores diferentes, localizados em cidades diferentes do estado do Rio Grande do Sul. Além da dificuldade do projeto, havia também a logística dos materiais chegarem à empresa para montagem. Destes, o fornecedor do componente que é a base para o início do processo de montagem localiza-se a 400 quilômetros.

A Tabela 1 mostra a participação de cada um destes cinco fornecedores de componentes especiais no custo de componentes, levando em consideração $\mathrm{o}$ valor dos materiais adquiridos para a fabricação do modelo básico.

Analisando os dados da Tabela 1, os cinco fornecedores escolhidos respondem por $61,76 \%$ do valor dos produtos adquiridos pela empresa para a produção do modelo básico. Em número de itens, estes fornecem dez dos oitenta e nove itens nacionais utilizados na montagem do modelo básico do produto. Isso representa 11,24\%. Assim, tem-se um número pequeno de itens representando um alto custo para a empresa. Além disso, o fornecedor 1, que entrega os componentes iniciais do processo representa $31,88 \%$ do custo, ou aproximadamente um terço do valor das peças adquiridas de terceiros.

Isso faz com que a empresa tenha maior atenção com este fornecedor, pois além do custo dos componentes, o atraso ou problemas de qualidade nos dois componentes fornecidos atrasa todo o restante do processo.

Por desconhecer a forma de montagem e a utilização de seus componentes no produto final, os fornecedores, muitas vezes, não cumpriam com o projeto original ou com as especificações solicitadas. Isso causou vários atrasos no processo de montagem dos produtos, pois em alguns casos houve a necessidade de devolução de materiais e, em outros casos houve o retrabalho dos componentes para montagem. A Figura 3 mostra a participação dos cinco fornecedores de produtos especiais no processo produtivo da empresa.

Pela Figura 3, observa-se que a empresa trabalhava com um modelo de produção empurrada, onde a programação da produção era enviada para o

Tabela 1. Participação dos fornecedores no custo de aquisição de componentes.

\begin{tabular}{|c|c|c|c|}
\hline Fornecedor & $\begin{array}{c}\text { Número de itens } \\
\text { fornecidos }\end{array}$ & $\begin{array}{c}\text { Participação de cada item nos } \\
\text { custos dos componentes do } \\
\text { modelo básico }\end{array}$ & $\begin{array}{c}\text { Participação do fornecedor } \\
\text { no custo dos componentes do } \\
\text { modelo básico }\end{array}$ \\
\hline 1 & 2 & $15,94 \%$ & $31,88 \%$ \\
\hline 2 & 2 & $3,25 \%$ & $6,50 \%$ \\
\hline 3 & 2 & $6,91 \%$ & $13,82 \%$ \\
\hline 4 & 1 & $0,92 \%$ & $0,92 \%$ \\
\hline 5 & 3 & $2,88 \%$ & $8,64 \%$ \\
\hline
\end{tabular}


início do processo e a partir desse iniciava-se a fabricação. Além disso, os quatro operadores da linha de produção realizavam todas as atividades de montagem, 1, 2, 3 e 4.

Os fornecedores principais entram em etapas distintas no processo de produção. $\mathrm{O}$ fornecedor 1 atua na primeira etapa de montagem. Assim, sem esses componentes nenhuma outra atividade poderia ser realizada. $\mathrm{O}$ fornecedor 2 entrega dois componentes apenas. Mesmo assim, sem estes componentes outras atividades podem ser realizadas, mas uma das principais funções do produto final não é atendida; além de outras atividades não poderem ser realizadas, pois são a colocação de outros componentes sobre esse. Os fornecedores 3 , 4 e 5 entregam itens para a conclusão do processo de montagem, sem os quais o produto não pode ser entregue para a quarta etapa, onde são realizados os acabamentos e inspeções de funcionamento. Os problemas encontrados com maior frequência para cada fornecedor foram:

Fornecedor 1: problema de alinhamento dos componentes quando montados e furos com diâmetro menor que o especificado no projeto;

Fornecedor 2: dificuldade em atender aos prazos de entrega e variação da espessura dos componentes;
Fornecedor 3: qualidade do componente, sendo que não havia padrão nos diferentes lotes recebidos pela empresa estudada;

Fornecedor 4: não atendimento do prazo de entrega; e

Fornecedor 5: variabilidade nas especificações.

Para adequar a empresa ao sistema de produção JIT, inicialmente foram tomadas ações internas, como a capacitação e especialização dos montadores, distribuindo-os em atividades individuais. Ou seja, cada montador tornou-se responsável pela realização de uma etapa da montagem, com sequência definida de cada etapa, como mostra a Figura 4. Desta forma a organização acabou alterando o seu leiaute. Inicialmente a produção trabalhava com um leiaute de posição fixa, onde o produto era fixo e a movimentação era feita pelos operadores e máquinas, para um leiaute por produto que leva a um fluxo contínuo. Os trabalhadores foram divididos e cada um ficou responsável por uma atividade, onde o produto passava por estes operadores formando uma linha de produção.

Outra medida fundamental foi a entrega da programação apenas para o setor de expedição. Isso foi feito com a criação de um quadro onde se preenche a data de entrega, o produto a ser fabricado

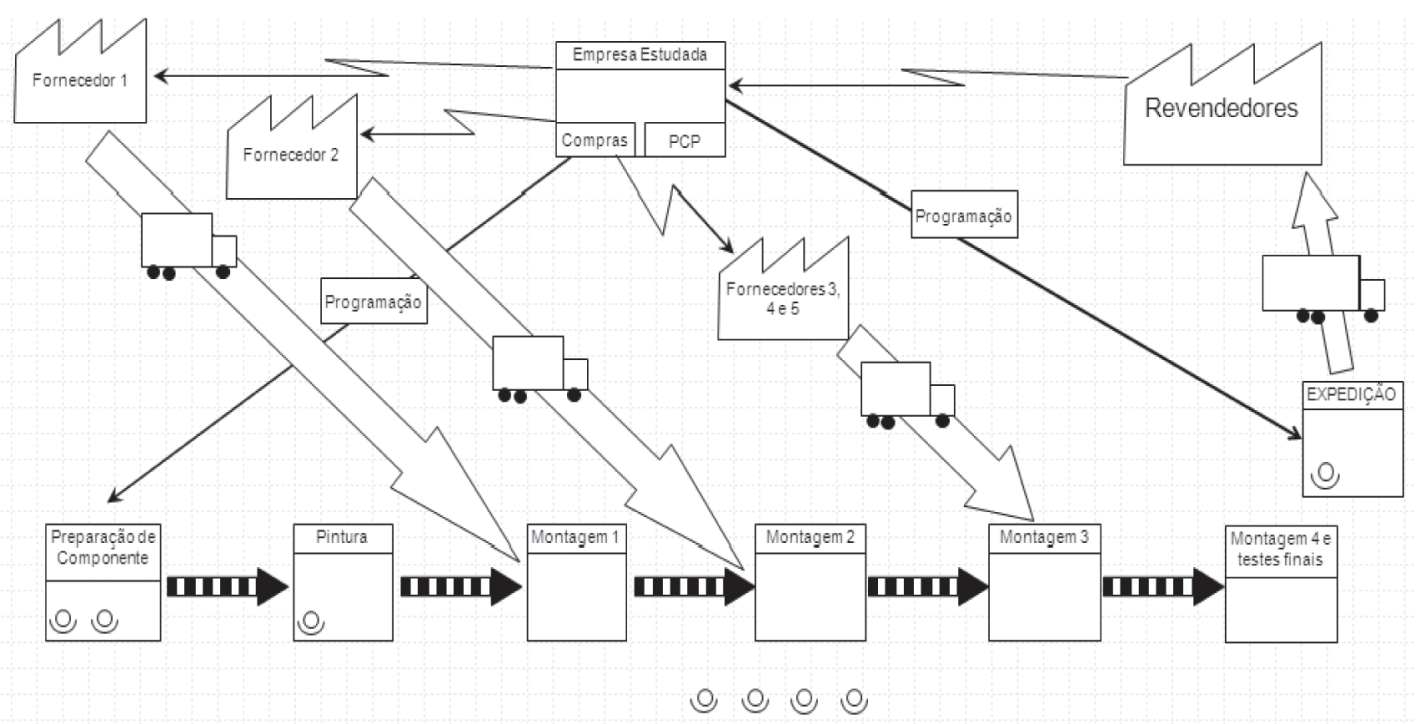

Figura 3. Envolvimento dos principais fornecedores no processo. 


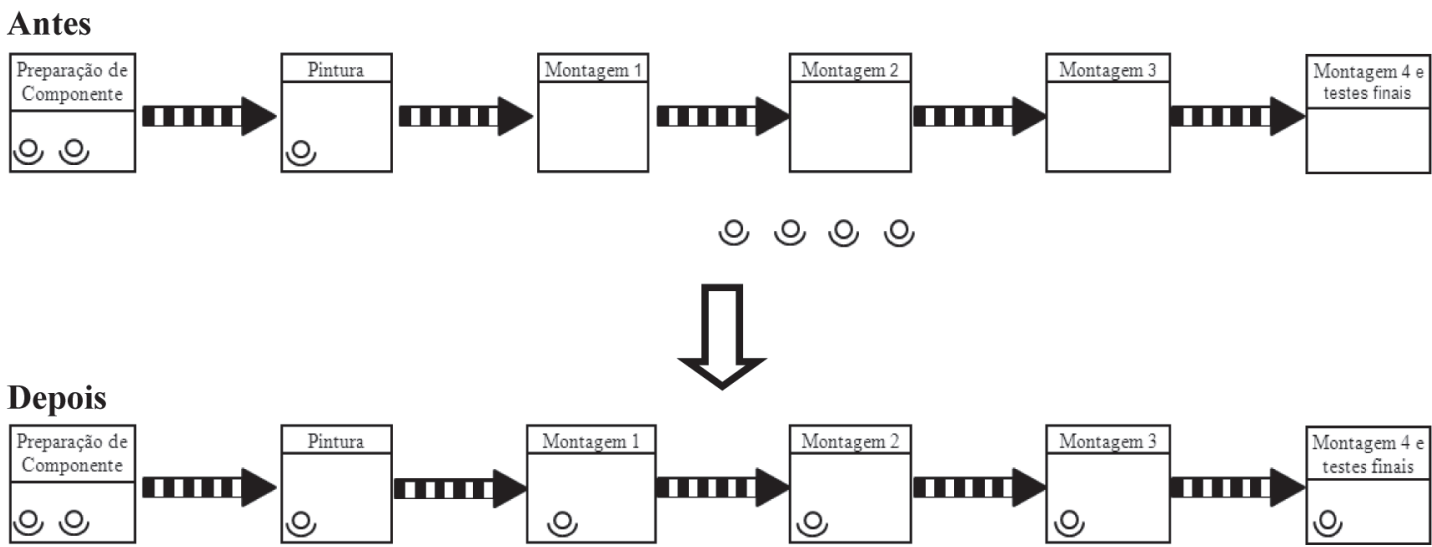

Figura 4. Alocação inicial das pessoas e após a implantação do JIT.

e o cliente. Com isso, passou-se a produzir os produtos de acordo com a prioridade de entrega e cada montador passou a receber suas peças separadas em kits, onde o almoxarifado entrega em cada posto de trabalho, caixas contendo a quantidade exata de peças e componentes a serem utilizadas no modelo em produção.

Para que as duas primeiras etapas do processo fossem abastecidas corretamente com os insumos comprados do fornecedor 1 e 2, a empresa passou a se responsabilizar pela contratação do frete dos componentes. Como os fornecedores pertencem a uma mesma rota rodoviária a organização desenvolveu uma parceria com uma transportadora que a cada 15 dias realizava a coleta do material no fornecedor 1 pela manhã e no fornecedor 2 na parte da tarde, garantindo o abastecimento de sua linha de produção.

Após essas mudanças, a empresa conseguiu reduzir o tempo de ciclo de cada equipamento em $14,28 \%$. Além de reduzir o tempo de produção de cada equipamento, houve melhoria da qualidade porque os montadores foram qualificados em funções específicas. Outras mudanças realizadas para conseguir-se alcançar esses resultados, foram: a mudança de leiaute do setor de montagem, com a separação das duas linhas de produtos, que passaram a ser montadas em linhas diferentes; a colocação de ferramentas de montagem ao lado do posto de trabalho de cada montador; a substituição de ferramentas manuais por pneumáticas; confecção de gabaritos de montagem para substituir a medição por trenas e paquímetros e o desenvolvimento de novos fornecedores para componentes-chave do produto.
A Figura 5 ilustra o novo fluxo de informações; de materiais vindos dos fornecedores 1 e 2; e a alocação dos montadores em suas funções específicas.

Para ampliar a utilização da metodologia JIT, a empresa está formando parcerias com seus fornecedores, para os quais está sugerindo a manutenção de seus estoques nos fornecedores, com pagamento antecipado dos custos de produção e o restante no momento do faturamento da mercadoria. Individualmente, a empresa está auxiliando os fornecedores avaliados a eliminarem seus problemas de processo de modo a melhorar seus componentes. As medidas que estão sendo propostas são:

Fornecedor 1: para resolver os problemas de qualidade deste fornecedor foi proposta a construção de gabaritos para a soldagem das peças no fornecedor, sendo que os custos desses serão arcados pela solicitante; e, para resolver o problema de dimensão dos furos estão sendo alterados os projetos para que os furos sejam de acordo com os padrões de furação já adotados pelo fornecedor;

Fornecedor 2: para evitar esses problemas a empresa está solicitando ao fornecedor que este construa matrizes individuais para cada um dos componentes fornecidos, evitando assim a demora em função da preparação das máquinas, o que auxiliará na melhoria da qualidade e no atendimento dos prazos de entrega;

Fornecedor 3: para reduzir a ocorrência de problemas de qualidade, a empresa está desenvolvendo novo projeto do conjunto fornecido por este fornecedor 


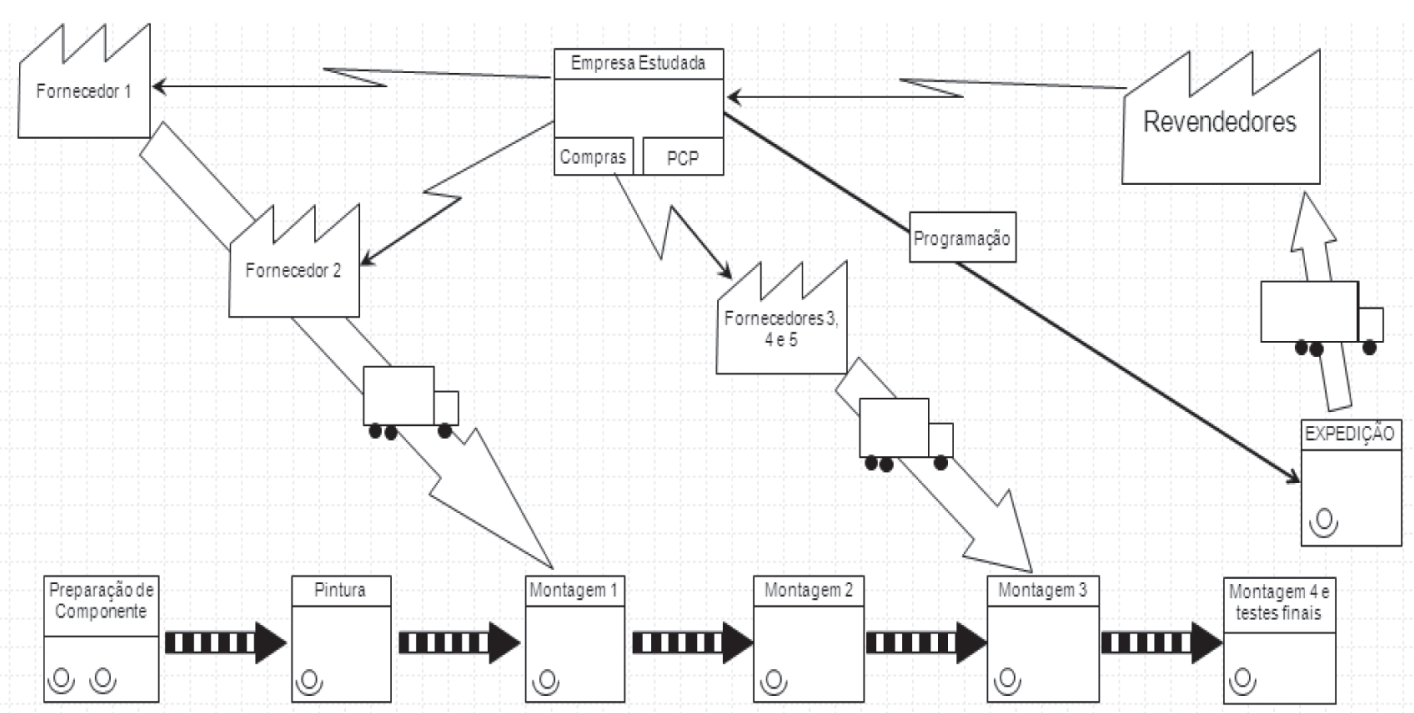

Figura 5. Novo fluxo de informações e de pessoas.

para reduzir as variações nos produtos para que o fornecedor tenha mais facilidade na fabricação dos componentes fornecidos;

Fornecedor 4: como o custo e o espaço dos componentes fornecidos por este fornecedor representam um percentual pequeno no produto final, foi modificado o método de compra e aumentada a quantidade solicitada ao fornecedor e mantido em estoque na própria empresa;

Fornecedor 5: por se tratar de um item de segurança na operação do equipamento, a empresa está auxiliando diretamente no processo do fornecedor, estudando as causas da variabilidade e na realização de estudos de viabilidade para a mudança de equipamento e a adoção de novos métodos de controle da qualidade.

\section{CONCLUSÕES}

Observando a situação inicial da empresa, considerase que a aplicação da filosofia de manufatura enxuta do processo interno da empresa, representou uma redução do tempo de ciclo de $14,28 \%$ com mudanças no método de trabalho e com pequenos investimentos em ferramentas. A partir dessas melhorias, observou-se que a produção JIT pode ser aplicada a empresas de qualquer ramo de atuação, neste caso a indústria de equipamentos agrícolas, independente do tamanho, visto que a empresa estudada é de pequeno porte.
Considerando o sucesso da aplicação do JIT nas operações industriais da empresa, espera-se que as propostas realizadas para os fornecedores sejam aceitas, pois além do conhecimento adquirido, a empresa auxiliará financeiramente seus fornecedores no desenvolvimento e fabricação de gabaritos e matrizes. Esse investimento significará melhorias para os fornecedores, que a partir de então serão tratados como parceiros. Para a empresa, esse investimento será revertido em garantia de entrega no prazo, melhoria de qualidade dos componentes e maior confiança na relação entre fornecedores e clientes. Todas estas melhorias serão revertidas no melhor atendimento aos clientes finais da empresa, ou seja os revendedores de seus produtos. Assim, espera-se uma maior credibilidade no fabricante, o que poderá se tornar um diferencial para torná-lo mais competitivo frente aos concorrentes e assim, aumentar as vendas de seus produtos.

O objetivo inicial deste trabalho foi aplicar o JIT no processo produtivo do fabricante de equipamentos agrícolas, para reduzir o número de atrasos na entrega causado pelo alto lead-time. Com a redução no tempo de ciclo de cada equipamento, conseguiu-se realizar todas as entregas atrasadas e com um ajuste nas datas dos equipamentos vendidos após o início deste estudo, considerando o tempo necessário para produzir o número de peças atrasadas, conseguiu-se atender aos demais pedidos no prazo determinado pelo planejamento e controle da produção-PCP. Isso 
aumentou a satisfação dos clientes e melhorou o relacionamento com os revendedores.

Com isso, considera-se que os objetivos propostos foram atendidos e sugere-se que a empresa estenda a filosofia JIT para a outra linha de produtos e para outros setores da empresa, como o setor administrativo, de fabricação de componentes, almoxarifado e prestação de serviços de assistência técnica. Além da tomada de ações internas sugere-se que o trabalho realizado junto aos cinco fornecedores desenvolvido durante esse estudo seja ampliado aos demais fornecedores. Isso auxiliará a empresa a reduzir seus níveis de estoque, com menor utilização de área física e de custo financeiro da manutenção destes.

\section{REFERÊNCIAS}

[1] I.P.S. Ahuja and J.S. Khamba. "Assessment of contributions of successful TPM initiatives towards competitive manufacturing". Journal of Quality in Maintenance Engineering. Vol. 14, Issue 4, pp. 356-374. 2008.

[2] A.G. Alves F., A.L. Cerra, J.L. Maia, M.S. Neto e P.V.G. Bonadio. "Pressupostos da gestão da cadeia de suprimentos: evidências de estudos sobre a indústria automobilística". Gestão \& Produção. Vol. $11 \mathrm{~N}^{\mathrm{o}}$ 3, pp. 275288. 2004.

[3] J.G. Arca and J.C. Prado. "Personnel participation as a key factor for success in maintenance program implementation". International Journal of Productivity and Performance Management. Vol. 57, Issue 3, pp. 247-258. 2008.

[4] C. Baudin. "Criterios de transferibilidad del enfoque concurrente en los procesos de diseño y desarrollo de productos de las pequeñas y medianas empresas chilenas". Ingeniare. Revista chilena de ingeniería, Vol. $19 \mathrm{~N}^{\circ} 1$, pp. 146-161. 2011.

[5] T.A. Boyle and M. Scherrer-Rathje. "An empirical examination of the best practices to ensure manufacturing flexibility”. Journal of Manufacturing Technology Management. Vol. 20, Issue 3, pp. 348-366. 2009.

[6] A.M.G. de Castro, S.M.V. Lima e C.M.P.N. Cristo. "Cadeia produtiva: marco conceitual para apoiar a prospecção tecnológica". XXII
Simpósio de Gestão e Inovação Tecnológica. Salvador. 2002.

[7] E. Cudney and C. Elrod. "A comparative analysis of integrating lean concepts into supply chain management in manufacturing and service industries". International Journal of Lean Six Sigma. Vol. 2, Issue 1, pp. 5-22. 2011.

[8] K.W. Green Jr., R.A. Inman and L.M. Birou. "Impact of JIT-selling strategy on organizational structure". Industrial Management \& Data Systems. Vol. 111, Issue 1, pp. 63-83. 2011.

[9] M. Hallgren and J. Olhager. "Lean and agile manufacturing: external and internal drivers and performance outcomes". International Journal of Operations \& Production Management. Vol. 29, Issue 10, pp. 976999. 2009.

[10] J.K. Liker. "O modelo Toyota: 14 princípios de gestão do maior fabricante do mundo". Bookman. Porto Alegre, Brasil. 2005.

[11] S.P. Low and M.Y. Show. "Facilities design incorporating just-in-time principles for rampup light factories in Singapore". Facilities. Vol. 26, Issue 7/8, pp. 321-342. 2008.

[12] M.A. daS. Macedo eA.G. Canen. "Diversidade cultural e prestação de serviços logísticos: um estudo exploratório". Ingeniare. Revista chilena de ingeniería. Vol. $17 \mathrm{~N}^{\circ} 3$, pp. 412422. 2009.

[13] P. Marksberry, F. Badurdeen, B. Gregory and K. Kreafle. "Management directed kaizen: Toyota's Jishuken process for management development". Journal of Manufacturing Technology Management. Vol. 21, Issue 6, pp. 670-686. 2010.

[14] J.E. Matson e J.O. Matson. "Just-in-time implementation issues among automotive suppliers in the southern USA". Supply Chain Management: An International Journal. Vol. 12, Issue 6, pp. 432-443. 2007.

[15] M.Z. Meybodi. "Benchmarking performance measures in traditional and just-in-time companies". Benchmarking: An International Journal. Vol. 16, Issue 1, pp. 88-102. 2009.

[16] R.A. Moura. "Sistema kanban de manufatura "just-in-time": uma introdução às técnicas de manufaturas japonesas". Instituto de Movimentação e Armazenagem de Materiais, São Paulo, Brasil. 1984. 
[17] L.S. Pheng, F.M. Arain and J.W.Y. Fang, "Applying just-in-time principles in the delivery and management of airport terminal buildings". Built Environment Project and Asset Management. Vol. 1, Issue 1, pp. 104121. 2011.

[18] S.R.I. Pires e M.S. Neto. "Características estruturais, relacionais e gerenciais na cadeia de suprimentos de um condomínio industrial na indústria automobilística". Produção. Vol. $20 \mathrm{~N}^{\circ}$ 2, pp. 172-185. 2010.

[19] S. Rahman, T. Laosirihongthong e A.S. Sohal. "Impact of lean strategy on operational performance: a study of Thai manufacturing companies". Journal of Manufacturing Technology Management. Vol. 21, Issue 7, pp. 839-852. 2010.

[20] M. Rodrigues e K. Hatakeyama. "Analysis of the fall of TPM in companies". Journal of Materials Processing Technology. Vol. 179, Issue 1-3, pp. 276-279. 2006.

[21] E. Rodríguez-Ponce, L. Pedraja-Rejas, M. Delgado y J. Rodríguez-Ponce. "Gestión del conocimiento, liderazgo, diseño e implementación de la estrategia: un estudio empírico en pequeñas y medianas empresas". Ingeniare. Revista chilena de ingeniería. Vol. 18 N $^{\circ}$ 3, pp. 373-382. 2010.

[22] M. Rother e J. Shook. "Aprendendo a enxergar: mapeando o fluxo de valor para agregar valor e eliminar o desperdício”. Lean Institute Brasil. São Paulo, Brasil. 2003.

[23] S. Shingo. "O sistema Toyota de produção do ponto de vista da Engenharia de Produção". Artes Médicas. $2^{\circ}$ Ed. Porto Alegre, Brasil. 1996.

[24] S. Taj. "Lean manufacturing performance in China: assessment of 65 manufacturing plants". Journal of Manufacturing Technology Management. Vol. 19, Issue 2, pp. 217-234. 2008.

[25] S. Taj e C. Morosan. "The impact of lean operations on the Chinese manufacturing performance". Journal of Manufacturing Technology Management. Vol. 22, Issue 2, pp. 223-240. 2011. 